\title{
Temporal and spatial variation characteristics of temperature and its impact on grain production in Northeast China in recent 50 years
}

Weiping Yan ( $\sim$ yanweiping0@126.com )

Jilin Academy of Agricultural Sciences

Hongxiang Zhao

Jilin Academy of Agricultural Sciences

Lihua Zhang

Jilin Academy of Agricultural Sciences

Chen Xu

Jilin Academy of Agricultural Sciences

Guobo Tan

Jilin Academy of Agricultural Sciences

Ning Sun

Jilin Academy of Agricultural Sciences

Fei Li

Jilin Academy of Agricultural Sciences

Xiangmeng Meng

Jilin Academy of Agricultural Sciences

Yan Gu

Jilin Agricultural University

Shaofeng Bian

Jilin Academy of Agricultural Sciences

\section{Research Article}

Keywords: Northeast China, climate warming, mean temperature, temporal and spatial distribution, food production

Posted Date: November 30th, 2021

DOI: https://doi.org/10.21203/rs.3.rs-1098462/v1

License: (c) (1) This work is licensed under a Creative Commons Attribution 4.0 International License.

Read Full License 


\section{Abstract}

Climate warming has a great impact on grain production in northeast China, but there are few studies on the temporal and spatial variation characteristics of annual Tmean (mean temperature), the impact of meteorological factors on Tmean, and the impact of Tmean increase on grain production in northeast China. This study found that annual Tmean decreased from southeast to northwest in Northeast China, and there were regional differences in spatial distribution. The annual Tmean isoline in Northeast China moves obviously from southeast to northwest. The annual warming trend of Tmean was significant from 1971 to 2000 , and moderated from 2001 to 2020 . In recent 50 years, Tmean had obvious periodic changes. In the mid-late 1980s, annual Tmean had a sudden warming change, and since then it has been rising continuously. Sunshine hours, average wind speed, evaporation and average air pressure had a very significant correlation with Tmean. In conclusion, the climate change in northeast China in the past 50 years has an obvious warming and drying trend, and there are regional differences in the warming and drying. The warming and drying climate has brought challenges to agricultural production and food security in Northeast China. However, the negative effects of grain production reduction caused by warming and drying climate can be avoided to a certain extent if we deal with it properly.

\section{Introduction}

The fifth assessment report of intergovernmental panel on climate change (IPCC) predicts that the world will continue to heat up in the 21 st century ${ }^{1,2}$. Global warming has significantly reduced ice cap, tundra, and boreal climate, and expanded temperate climates, dry climates and savanna climates ${ }^{3}$. The blue book on climate change in China (2021) points out that the trend of global warming continues. The average land surface temperature of Asia in 2020 is $1.06{ }^{\circ} \mathrm{C}$ higher than the annual value, which is the warmest year since the beginning of the 20th century, the period from 2011 to 2020 was the warmest decade since $1850^{4}$. As the key meteorological element of regional response and mutual feedback of global climate change, the characteristics of temperature change have attracted more and more attention ${ }^{5,6}$. China is one of the most vulnerable regions to climate change in the world. Climate change has a profound impact on sustainable economic and social development and poses a serious threat to food security, ecological security and water resources security ${ }^{7,8}$. Climate change will increase the instability of agricultural production, increase the fluctuation of output, and change the layout and structure of agricultural production ${ }^{9-11}$. Climate change has aggravated the comprehensive land pressure, seriously affected the global food security, and increased the disaster risk and loss of agricultural production, especially in some vulnerable regions ${ }^{12}$. Climate change has led to the shift of climate zone. High temperature heat wave, drought and cold wave begin to appear in new regions. The expansion of arid and semi-arid regions affects the planting of crops in different regions ${ }^{13-15}$. In the context of global warming, meteorological disasters such as drought and flood have had a serious impact on crops in Northeast China ${ }^{16,17}$. 
Northeast China is an important major grain producing area in China. The basic characteristics of the ground in Northeast China are that water surrounds mountains and fertile fields are thousands of miles. The soil in this area is black soil, with vertical and horizontal hydrothermal conditions, and there is great potential for grain production. Northeast China consists of Heilongjiang, Jilin and Liaoning provinces and four league cities in eastern Neimenggu (hereinafter referred to as East-Neimenggu). Heilongjiang Province ranks first in the country in terms of land conditions and is one of the three famous black soil belts in the world. Heilongjiang Province ranks first in the country in terms of land conditions and is one of the three famous black soil belts in the world. Songliao Plain in the middle of Jilin Province has fertile soil and is known as "golden corn belt" and "hometown of black land". It is an important commercial grain production base in China. Hulunbeier grassland in East-Neimenggu is one of the four grasslands in the world and is known as the best grassland in the world.

Climate warming and its negative effects have brought severe challenges to food security in Northeast China. In order to ensure regional food security and effectively deal with the adverse effects of climate warming, the impact of climate warming in Northeast China was studied ${ }^{18,19}$. Based on the meteorological data of international meteorological exchange station in Northeast China from 1971 to 2020 , this paper studies the temporal and spatial distribution characteristics of Tmean in recent 50 years, analyzes the interaction between sunshine duration, wind speed, evolution, pressure and Tmean, and discusses the impact of climate warming on agricultural production and food security in Northeast China. Reveal the temporal and spatial variation law of Tmean in Northeast China and the correlation between meteorological elements. It is hoped to provide reference for the sustainable agricultural development and regional food security in Northeast China.

\section{Result}

\section{Spatial distribution characteristics of annual Tmean.}

Based on the meteorological data of 34 ground international exchange stations, the spatial distribution and change of annual Tmean in Northeast China are analyzed. From 1971 to 2020, the annual Tmean in Northeast China generally decreased from southeast to northwest, and the annual Tmean was about $-4.2-11.2^{\circ} \mathrm{C}$ (fig.1). In Liaoning Province in the south of Northeast China, the annual Tmean decreased from south to north, and the annual Tmean was about $7-11.2^{\circ} \mathrm{C}$ (fig.1). In Jilin Province in the Middle East of Northeast China, the annual Tmean decreased from southwest to northeast, and the annual Tmean was about $4-7^{\circ} \mathrm{C}$ (fig.1). In Heilongjiang Province in the north of Northeast China, the annual Tmean decreases from southwest to northeast and from southeast to northwest, and the annual Tmean is about $-0.7-5^{\circ} \mathrm{C}$ (fig.1). The annual Tmean in East-Neimenggu where belongs to the west of Northeast China decreased from south to north, and the annual Tmean was about $-4.2^{\circ} \mathrm{C}-8^{\circ} \mathrm{C}$.

The highest Tmean was found in the southern part of Liaoning Province, and the highest Tmean was above $11.2^{\circ} \mathrm{C}$ (fig.1). The annual Tmean of Hulunbeier in the west of East-Neimenggu is the decade between the South and north of East-Neimenggu is the largest (fig.1). 


\section{Temporal variation trend of annual Tmean.}

The period from 1971 to 2020 is divided into five periods. D1 represents the period from 1971 to 1980, D2 represents the period from 1981 to 1990, D3 represents the period from 1991 to 2000, D4 represents the period from 2001 to 2010, and D5 represents the period from 2011 to 2020. The annual Tmean of Northeast China in any decade generally decreases from southeast to northwest $囚$ in this area the annual Tmean isoline moves from southeast to northwest (Fig.2).

$\mathrm{D} 1$, the annual Tmean of Liaoning province is about $6-10{ }^{\circ} \mathrm{C}$, the annual Tmean of Jilin province is about $4-6{ }^{\circ} \mathrm{C}$, the annual Tmean of Heilongjiang province is about $-1-4{ }^{\circ} \mathrm{C}$, and the annual Tmean of East-Neimenggu is between $-4-7^{\circ} \mathrm{C}$ (Fig.2-A). D2, the annual Tmean of Liaoning province is about $7-10{ }^{\circ} \mathrm{C}$, the annual Tmean of Jilin province is about $4-6^{\circ} \mathrm{C}$, the annual Tmean of Heilongjiang province is about $0-4{ }^{\circ} \mathrm{C}$, and the annual Tmean of East-Neimenggu is between $-4-8{ }^{\circ} \mathrm{C}$ (Fig.2-B). D3, the annual Tmean of Liaoning province is about $8-11^{\circ} \mathrm{C}$, that of Jilin province is about $5-7{ }^{\circ} \mathrm{C}$, that of Heilongjiang province is about $0-5^{\circ} \mathrm{C}$, and that of East-Neimenggu is $-3-8{ }^{\circ} \mathrm{C}$ (Fig.2-C). D4, the annual Tmean of Liaoning province is about $8-11.5^{\circ} \mathrm{C}$, that of Jilin Province is about $5-7{ }^{\circ} \mathrm{C}$, that of Heilongjiang province is about $1-5^{\circ} \mathrm{C}$, and that of East-Neimenggu is about $-3-8{ }^{\circ} \mathrm{C}$ (Fig.2-D). In these areas, the annual Tmean of D5 period is close to that of D4 period (Fig.2-E).

Fig.2, During D1, D2 and D3, the annual Tmean in Northeast China increases significantly, the hightemperature area increases significantly, the low-temperature area decreases, and the annual Tmean isoline in Northeast China moves significantly from southeast to northwest. In D4 period, compared with D1 period, the low-temperature range in the northwest of Northeast China is gradually narrowing, and the high-temperature range in the southeast is increasing. During D4 and D5, the annual Tmean warming in Northeast China slowed down, and the annual Tmean has been maintained at a high level. During D1 - D5 periods, the annual Tmean of Liaoning province is the highest, the annual Tmean of south East-Neimenggu, Jilin province and most parts of Heilongjiang province is in the middle, and the annual Tmean of north East-Neimenggu and northwest Heilongjiang province is the lowest (Fig.2).

\section{Anomaly analysis of annual Tmean.}

Fig.3-A, In recent 50 years, the annual Tmean in Northeast China has increased significantly, and the average temperature increasing rate is about $0.31^{\circ} \mathrm{C} / 10 \mathrm{a}$. Using the previously divided time periods $\mathrm{D} 1$, D2, D3, D4 and D5, through calculation, it can be seen that D2 increases the temperature by about 0.45 ${ }^{\circ} \mathrm{C}$ compared with D1, D3 increases the temperature by about $0.56{ }^{\circ} \mathrm{C}$ compared with D2, D4 increases the temperature by about $0.18{ }^{\circ} \mathrm{C}$ compared with D3, and D5 increases the temperature by about $0.04{ }^{\circ} \mathrm{C}$ compared with D4. Taking 2000 as the boundary, the annual tmean in Northeast China fluctuated and 
increased significantly from 1971 to 2000 , and the temperature increase rate was about $0.5^{\circ} \mathrm{C} / 10 \mathrm{a}$. From 2001 to 2020, the annual tmean warming trend in Northeast China slowed down, and the warming rate was about $0.11^{\circ} \mathrm{C} / 10 \mathrm{a}$. The annual Tmean values of 1971, 1977, 1978, 1991, 1993, 1996, 2005 and 2018 are the closest to the trend line (Fig.3-A).

Fig.3-B, in recent 50 years, the annual Tmean in Northeast China showed a trend of low-high-low-high wave period, the wave period from 1971 to 2008 was longer, but the wave period from 2009 to 2020 was significantly shortened. From 1971 to 1988 , the annual Tmean anomaly column was mostly negative, and the anomaly column was longer, only 1975 and 1982 were positive anomaly values. The annual Tmean anomaly values fluctuated more frequently from the 1989 to 2008 , the positive anomaly columns and they are longer. The annual Tmean from 2009 to 2013 were all negative anomalies, and the annual Tmean from 2014 to 2020 were all positive anomalies.

\section{Time series mutation analysis of Tmean.}

Analysis of Mann-Kendall ( $a=0.05$, critical line \pm 1.96$)$ mutation of annual Tmean in northeast China in recent 50 years showed that annual Tmean had a warming trend from the mid-late 1980s, but it was not obvious (Fig.4). In the graph, UF curve and UB curve have an intersection between two critical value lines (Fig.4). According to the location of the intersection, the mutation time is 1988. Since 1990, the UF curve has exceeded the critical value line, and the annual Tmean has a significant temperature rise trend (Fig.4).

\section{Analysis of cyclical changes in Tmean.}

In the past 50 years, the annual Tmean of the northeast China existed high-frequency waves below 10a and low-frequency waves above 15a, and the high-frequency waves appeared frequently from 1971 to 2020 (Fig.5). The annual Tmean had the strongest periodic oscillation at about 7a, with obvious periodic change. There were several high-frequency cycles in annual Tmean before 1983. Tmean from 1984 to 1987 is a high-frequency period. From 1989 to 2013, there was a low-frequency period in Tmean, and multiple high-frequency periods were included in the low-frequency period (Fig.5). During this period, the annual temperature of Tmean increased significantly. The annual Tmean showed a new cycle change after 2014, and the cycle did not close in 2020, indicating that the cycle change was not finished (Fig.5).

\section{Correlation analysis of meteorological factors.}

Tab.1 Correlation analysis of meteorological factors. 


\begin{tabular}{llllll}
\hline & Tmean & $\begin{array}{l}\text { Sunshine } \\
\text { duration }\end{array}$ & $\begin{array}{l}\text { Wind } \\
\text { speed }\end{array}$ & Evaporation & Pressure \\
\hline Tmean & - & & & & \\
Sunshine duration & $0.44^{* *}$ & - & & & \\
\hline Wind speed & $0.38^{* *}$ & $0.51^{* *}$ & -- & & \\
\hline Evaporation & $0.71^{* *}$ & $0.68^{* *}$ & $0.72^{* *}$ & -- & - \\
\hline Pressure & $0.43^{* *}$ & $0.22^{* *}$ & -0.14 & $0.24^{* *}$ & - \\
\hline
\end{tabular}

Note: $* \mathrm{p}<0.05, * * \mathrm{p}<0.01$. Wind speed refers to the average wind speed every 2 minutes.

The results of correlation analysis show that Tmean is significantly correlated with sunshine duration, wind speed, evaporation and pressure (Tab.1). Sunshine duration is significantly correlated with wind speed, evaporation and pressure. The wind speed is significantly correlated with evaporation. Evaporation has a very significant correlation with pressure.

\section{Spatial distribution of relevant meteorological factors.}

In recent 50 years, the average annual sunshine duration in Northeast China decreased from west to east, and the average annual sunshine duration was about 2210 - $3000 \mathrm{~h}$ (Fig.6-A). The average annual sunshine duration in East-Neimenggu is the highest, which can reach about $3003 \mathrm{~h}$. The average annual sunshine duration in the eastern part of Jilin province and the southeastern part of Heilongjiang province is relatively low, and the average annual sunshine duration in the eastern part of Jilin province is the lowest, which can reach about $2216 \mathrm{~h}$ (Fig.6-A).

In recent 50 years, the average annual wind speed in Northeast China has obvious differences in different regions, and the average annual wind speed is about $1.2-4.2 \mathrm{~m} / \mathrm{s}$. The average annual wind speed in Heilongjiang province is generally large, but the average annual wind speed of the regions near the Greater Khingan Mountains and Lesser Khingan Mountains is relatively small, about $2 \mathrm{~m} / \mathrm{s}$ (Fig.6-B). The average annual wind speed of Jilin province varies significantly from the east to the west, and the region near the Changbai Mountains has the lowest average annual wind speed of about $1.3 \mathrm{~m} / \mathrm{s}$ (Fig.6-B). The average annual wind speed of the region near the Greater Khingan Mountains in East-Neimenggu is relatively small, about $2.1 \mathrm{~m} / \mathrm{s}$ (Fig.6-B). The average annual wind speed of the areas near the branch of Changbai Mountain in Liaoning province is relatively small, while that of the coastal areas is relatively large (Fig.6-B).

In the last 50 years, the average annual evaporation in northeast China decreased from southwest to periphery, and the average annual evaporation was about $1000-2000 \mathrm{~mm}$ (Fig.6-C). The average annual evaporation is relatively high in the southern part of East-Neimenggu and the southwestern part of Liaoning province, and it is the highest in the southwestern part of Liaoning province, which can reach about $2018 \mathrm{~mm}$ (Fig.6-C). The average annual evaporation in the northern part of East-Neimenggu is the lowest, up to about $967 \mathrm{~mm}$ (Fig.6-C). In recent 50 years, the average annual pressure in Northeast China 
decreased from east to west, and the average annual pressure was about 890 - 1010 hpa (Fig.6-D). The average annual pressure of Heilongjiang province is about $980-1000 \mathrm{hpa}$, while the average annual Pressure of the areas near the Greater Hinggan Mountains is relatively low (Fig.6-D). The average annual pressure in Jilin province is about $980-990 \mathrm{hpa}$, and the change of the average annual pressure in Jilin province is the smallest (Fig.6-D). The average annual pressure in Liaoning province is about $990-1010$ $\mathrm{hpa}$, and the average annual pressure in the southern coastal areas of Liaoning province is the highest in northeast China (Fig.6-D). The average annual pressure in East-Neimenggu is about $890-990 \mathrm{hpa}$, and the average annual pressure in the west of the Greater Hinggan Mountains is relatively low, among which the average annual pressure in Xing'an league region is the lowest in Northeast China (Fig.6-D).

\section{Discussion}

\section{Spatial distribution of annual Tmean.}

Northeast China is one of the regions with significant warming due to global warming and has unique characteristics of temperature change. The study found that the spatial distribution of annual Tmean decreased from southeast to northwest in Northeast China in the past 50 years, and the spatial distribution of annual Tmean had obvious regional differences, which was similar to the research results of Dongsheng Zhao ${ }^{23}$ et al. The regional difference between the southern and northern parts of Northeast China is the most significant, and the warming amplitude of different regions is obviously different. From the 1960 s to the early 21 st century, the temperature increase trend was obvious in the boundary area of Jilin, Heilongjiang and East-Neimenggu, while the temperature increase was weak in the middle of Liaoning province and the center of East-Neimenggu near the border area ${ }^{24-26}$. Heilongjiang province had the largest temperature increase, followed by Jilin province.

\section{Temporal variation of annual Tmean.}

In recent 50 years, the annual Tmean in Northeast China has an obvious warming trend, with an increase of $0.31^{\circ} \mathrm{C}$ per decade, which verifies and extends the conclusions of Chunyu Zhao ${ }^{27}$ and Zhimei Guo ${ }^{28}$ et al. The study found that the temperature increase amplitude of annual Tmean in every decade in Northeast China is significantly different, and there are regional differences in the annual temperature increase amplitude of Tmean. From the 1970s to the end of the 20th century, the temperature increasing trend of annual Tmean in was significant, and the temperature increasing rate was about $0.5^{\circ} \mathrm{C} / 10 \mathrm{a}$. After 2000, the warming trend in Northeast China slowed down. The average annual temperature in China showed a warming trend as a whole, but the variation trend in each period was different ${ }^{29,30}$. After 2000, the average annual temperature in China showed an obvious stagnation phenomenon.

Before the 1980s, the temperature in China fluctuated in a small range, the warming rate showed an increasing trend in the mid-late 1980s, and the warming began to intensify in the early $1990 \mathrm{~s}^{31,32}$. Mannkendall mutation test was conducted on annual Tmean in Northeast China, and it was found that there was a significant warming mutation in annual Tmean in the mid-late 1980s (1988), and then the 
temperature in Northeast China continued to rise. which was consistent with the research conclusion of Lu Han ${ }^{33}$ and Xiaoyu Zhou ${ }^{34}$ that the warming mutation occurred in Northern China.

The annual Tmean in Northeast China has oscillation cycle of time variation 27,35 . The study found that in the past 50 years, the annual Tmean in Northeast China has a periodic change of less than 10a and more than 15 a. From 1990s to early 21 st Century, the annual Tmean of Northeast China changed periodically for many times. Low frequency periodic changes of more than $15 \mathrm{a}$ were accompanied by high frequency periodic changes of less than 10 a, so the warming process in Northeast China was oscillating. Since 2014 , there has been an unclosed low-frequency cycle, and it is considered that the temperature increase of Tmean will continue at this stage.

\section{The interaction of meteorological elements.}

Since 1960s, the climatic factors such as average sunshine duration, average wind speed and evaporation have decreased significantly in Northeast China ${ }^{27,36}$. According to the research, sunshine duration, wind speed, evaporation and air pressure are significantly correlated with Tmean change. With the continuous warming of climate, the intensity and frequency of precipitation in most parts of China tend to increase $\mathrm{e}^{37,38}$. Under the background of global warming, the response of evaporation to temperature rise changes significantly with different precipitation and climate types ${ }^{15}$. And there is a synchronous relationship between temperature, air pressure and surface wind speed ${ }^{39}$.

From the 1960 s to the early 21 st century, the annual sunshine duration in Heilongjiang province, Jilin province and Liaoning province tended to decrease, and there was a significant decrease mutation in the sunshine duration in the early $1980 \mathrm{~s}^{40-42}$. The study found that annual sunshine duration decreased from west to east in Northeast China in recent 50 years, with the strongest in the southern part of EastNeimenggu and the weakest in the eastern part of Jilin province. Temperature, humidity and wind speed have great correlation with sunshine duration, and wind speed is an important driving factor of sunshine duration reduction in northern China ${ }^{43-44}$.

In recent decades, the overall tend of surface wind speed in China is weakening, and there are obvious seasonal, regional and wind speed segment differences in surface wind speed ${ }^{45-47}$. The study found that in recent 50 years, the annual wind speed in different regions of Northeast China is obviously different. The annual wind speed in the areas near Greater Khingan Mountains, Lesser Khingan Mountains and Changbai mountains is relatively small, and the annual wind speed in coastal and plain areas is relatively large.

The variation of evaporation is significantly affected by temperature, humidity, wind speed and radiation ${ }^{48}$. The study found that the annual evaporation decreases from southwest to periphery in Northeast China in recent 50 years, and the annual evaporation has obvious regional difference. The rising temperature in the Northeast China region has increased the surface evaporation ${ }^{17}$. There are 
regional differences in the annual variation of evaporation, air temperature, sunshine duration, water vapor pressure, wind speed and atmospheric humidity have significant effects on evaporation ${ }^{49,50}$.

Under the background of climate warming, the pressure gradient force has obviously weakened in the past few decades, and there is an obvious correlation between the change of pressure gradient force and surface wind speed ${ }^{39}$. From the 1960 s to the beginning of the 21 st century, the average ground pressure in Heilongjiang province, Jilin province and Liaoning province has no obvious trend change, and the change characteristics of each region are different ${ }^{51}$.

\section{Effects of climate warming on food production.}

Climate change is a major challenge for mankind. To study the impact of climate change on agriculture is to answer the possible impact of climate change on food security, to explore the possible future actual food output under various climate conditions, so as to provide adaptive countermeasures and suggestions for the sustainable development of agriculture ${ }^{13,19}$. In 2014, the IPCC released its Fifth Assessment Report, which predicted that the impact of rising temperatures on yields of major crops would vary by crop, region and adaptation scenario ${ }^{52}$. China is a sensitive and significant area of global climate change, and climate warming has a significant impact on the stability and sustainability of China's agricultural production ${ }^{53-55}$. The increase of average temperature has a negative effect on the average yield of maize in China, but a significant positive effect on the yield of maize in eastern Northeast China ${ }^{56}$. With the warming of climate, the planting boundary of maize varieties in Northeast China has been moving northward and eastward, and the high value area of its climatic productivity potential has been moving northward ${ }^{10,11,14}$. The light temperature production potential and climate production potential of maize in Northeast China have a regional change trend affected by temperature ${ }^{57}$. A large number of data show that climate warming has a positive impact on crop yield in middle and high latitudes ${ }^{13,58}$. In the reclamation area of Heilongjiang province in Northeast China, the trend of climate warming is obvious. There is a significant positive correlation between temperature in growing season and rice yield. Under the background of climate warming, the temperature suitability of rice in Liaoning province showed a significant upward trend in each growth period, the suitability index increased by 0.05 for every $1{ }^{\circ} \mathrm{C}$ increase in the average temperature ${ }^{59}$.

Studies on the yield and temperature relationship at the regional scale show that more than half of cultivated land is vulnerable to the adverse effects of warming trend. In most major grain-producing areas, crop yield actually increases or does not change significantly due to better agronomic management measures (including adaptation) ${ }^{60-62}$. Adaptation to climate change is a key factor in determining the severity of the impact of future climate change on food production. The growth and yield of maize in Northeast China are gradually adapting to the warming and drying climat. Through the improvement of maize varieties and the adjustment of sowing date, we can fully tap the yield increasing effect of climate warming ${ }^{63}$. In addition, selecting maize varieties with long growth period, drought resistance and high temperature resistance in the arid and semi-arid areas of Northeast China, and 
adopting advanced agricultural irrigation water-saving technology and soil and water conservation technology can effectively deal with the warm and dry climate ${ }^{64}$.

In conclusion, the climate change in Northeast China in the past 50 years has an obvious warming and drying trend, and there are regional differences in the warming and drying. Climate warming and drying into Northeast China agricultural production and food security challenges, strengthen risk monitoring and early warning, cultivate strong adaptability of crop varieties, adopts to adapt to the climate in the agricultural production of dry cultivation techniques and management measures, etc., can effectively guarantee regional food security and mitigating climate warming, promote the sustainable development of agriculture.

\section{Data And Methods}

\section{Overview of the study region.}

Northeast China is located between $115^{\circ} 31^{\prime}-135^{\circ} 05^{\prime} \mathrm{E}$ and $38^{\circ} 4^{\prime}-53^{\circ} 33^{\prime} \mathrm{N}$, with a total land area of about 1271400 square kilometers, accounting for $13.2 \%$ of China's total land area (Fig.7). Heilongjiang province $\left(121^{\circ} 11^{\prime}-135^{\circ} 05^{\prime} \mathrm{E}, 43^{\circ} 26^{\prime}-53^{\circ} 33^{\prime} \mathrm{N}\right)$ is located in the northeast of China (Fig.7). It is the province with the highest longitude and latitude in China. The terrain is high in the northwest and southeast, and low in the northeast and southwest. Jilin province $\left(121^{\circ} 38^{\prime}-131^{\circ} 19^{\prime} \mathrm{E}, 40^{\circ} 50^{\prime}-46^{\circ} 19^{\prime}\right.$ $\mathrm{N}$ ) is located in the middle of Northeast China (Fig.7). The terrain is high in the southeast, and low in the northwest. Liaoning province $\left(118^{\circ} 53^{\prime}-125^{\circ} 46^{\prime} \mathrm{E}, 38^{\circ} 43^{\prime}-43^{\circ} 26^{\prime} \mathrm{N}\right)$ is located in the south of Northeast China (Fig.7). The terrain is characterized by high on the sides and low in the middle. EastNeimenggu $\left(115^{\circ} 31^{\prime}-126^{\circ} 04^{\prime} \mathrm{E}, 41^{\circ} 17^{\prime}-53^{\circ} 20^{\prime} \mathrm{N}\right)$ is located in the west of Northeast China, including Xing'an league, Hulunbuir city, Tongliao city and Chifeng city, accounting for $36.4 \%$ of the total area of Northeast China (Fig.7).

\section{Data sources.}

The meteorological data of the study area comes from China Meteorological Data Network (http://data.cma.cn/). Taking the annual meteorological data of 34 international meteorological exchange stations in Northeast China from 1971 to 2020 as the research object (Fig.8). This paper studies the temporal and spatial changes of Tmean in recent 50 years, as well as the spatial changes of sunshine duration, wind speed, evaluation and pressure.

\section{Spatial analysis and information map.}

ArcGIS 10.7 model is used for interpolation analysis, extraction analysis, surface analysis and expression of meteorological elements. Inverse Distance Weighted (IDW) interpolation method is used for interpolation analysis. Mask extraction method is used for extraction analysis. Contour tool in spatial analysis is used for surface analysis to extract corresponding isolines, and finally a complete meteorological geographic information map is generated. 


\section{Correlational analyses.}

Pearson analysis method was used to analyze the correlation of meteorological elements ${ }^{4}$.

\section{Mann-Kendall mutation test.}

Mann-Kendall method was used for mutation test of time series ${ }^{1}$. Mann-Kendall test is an effective tool recommended by (World Meteorological Organization (WMO) to extract sequence change trend and mutation. It is a nonparametric test method. It advantage is that it is not disturbed by outliers and can objectively reflect the trend of time series. It is widely used in mutation test of climate parameters.

\section{Wavelet analysis.}

Wavelet analysis method is used for periodic analysis ${ }^{2}$. Wavelet analysis, also known as multi-resolution analysis, is a basic mathematical means and is considered to be a breakthrough in Fourier analysis. In climate diagnosis, wavelet transform can not only give the scale of climate sequence change, but also show the time position of change, which is very useful for climate prediction.

\section{References}

1. IPCC. Climate Change 2013: The Physical Science Basis (ed. Stocker, T. F.)1217-1308(Cambridge University Press, 2014)

2. IPCC, Summary for policymakers. Climate change and land: an IPCC special report on climate change, desertification, land degradation, sustainable land management, food security, and greenhouse gas fluxes in terrestrial ecosystems. Preprint at https://www.ipcc.ch/srccl/chapter/summary-for-policymakers/ (2019)

3. Belda, M., Holtanová, E., Kalvová, J. \& Halenka, T. Global warming-induced changes in climate zones based on CMIP5 projections. Climate Res, 71, 17-31 (2016).

4. CMA Climate Change Centre. Blue Book on Climate Change in China 2021 (ed. Song, L. C.) 45-58 (Science Press, 2021)

5. Qi, Q. H., Cai, R. S. \& Guo, H. X. The climatic variations of temperature extremes in the Eastern of China. Scientia Geographica Sinica, 39, 1340-1350 (2019).

6. Wu, J. G., Zhai, P. M. \& Wu, Y. T. New understanding on the land-based response options to climate change. Climate Change Research, 16, 50-69 (2020).

7. Wu, S. H. \& Zhao, D. S. Progress on the impact, risk and adaptation of climate change in China. China Population \& Resources \& Environment, 30, 1-9 (2020).

8. Ye, L. M. et al. Climate change impact on China food security in 2050. Agron. Sustain. Dev, 33, 363374 (2013).

9. Zhou, S. D., Zhou, W. K., Zhu, H. G., Wang, C. X. \& Wang, Y. Impact of climate change on agriculture and its countermeasures. Journal of Nanjing Agricultural University (Social Sciences Edition), 10, 34- 
39 (2010).

10. Yuan, B., Guo, J. P., Ye, M. Z. \& Zhao, J. F. Variety distribution pattern and climatic potential productivity of spring maize in Northeast China under climate change. Chin. Sci. Bull, 57, 1252-1262 (2012).

11. Liu, Z. J. et al. The possible effects of global warming on cropping systems in China â... $£$. the possible impact of future climatic warming on the northern limits of spring maize in three provinces of Northeast China. Scientia Agricultura Sinica, 43, 2280-2291 (2010).

12. Jia, G. S. New understanding of land-climate interactions from IPCC special report on climate change and land. Climate Change Research, 16, 9-16 (2020).

13. Jia, G. S. et al. Land-climate interactions. Climate change and land: an IPCC special report on climate change, desertification, land degradation, sustainable land management, food security, and greenhouse gas fluxes in terrestrial ecosystems. Preprint at https://www.ipcc.ch/srccl/chapter/chapter-2/ (2019)

14. Yang, X. G., Liu, Z. J. \& Chen, F. The possible effects of global warming on cropping systems in China â...¥. possible effects of future climate change on northern limits of cropping system in China. Scientia Agricultura Sinica, 44, 1562-1570 (2011).

15. Zhang, Q., Yang, Z. S., Hao, X. C. \& Yue, P. Transition features of surface evapotranspiration responding to climate warming with spatial precipitation-based climate type in Northern China. Chin. Sci. Bull, 63, 1035-1049 (2018).

16. Li, Z. H., Liu, S., Guo, C. M. \& Wang, D. N. Predicting the impact of future climate change on rice yield in Northeast China. Journal of China Agricultural University, 20, 223-228 (2015).

17. Sun, F. H., Yang, S. Y. \& Chen, P. S. Climatic warming-drying trend in Northeastern China during the last 44 years and its effects. Chinese Journal of Ecology, 24, 751-755 (2005).

18. Yu, H. K. \& Guo, J. P. Variation in spatial and temporal distribution of chilling injury of rice under climate change in Northeast China. Chinese Journal of Eco-Agriculture, 22, 594-601 (2014).

19. Xu, Y. L., Zhao, Y. C. \& Zhai, P. M. Advances in scientific understanding on climate change and food security from IPCC special report SRCCL. Climate Change Research, 16, 37-49 (2020).

20. Shi, N. The Multi-analysis Method of Meteorological Research and Prediction (ed. Shi, N.) 58-100 (Meteorological Press, 2002)

21. Wei, F. Y. Modern Climate Statistical Diagnosis and Prediction Technology (ed. Wei, F. Y.) 43-134 (Meteorological Press, 2007)

22. Cui, J. T. An Introduction to Wavelets (ed. Cui, J. T.) 66-69 (Xi'an Jiaotong University Press, 1995)

23. Zhao, D. S., Gao, X., Wu, S. H. \& Zheng, D. Trend of climate variation in China from 1960 to 2018 based on natural regionalization. Advances in Earth Science, 35, 750-760 (2020).

24. Sun, F. H., Yang, X. Q., Lu, S. \& Yang, S. Y. The contrast analysis on the average and extremum temperature trend in Northeast China. Scientia Meteorologica Sinica, 26, 157-163 (2006). 
25. Jia, J. Y. \& Guo, J. P. Characteristics of climate change in Northeast China for last 46 years. Journal of Arid Land Resources and Environment, 25, 109-115 (2011).

26. Ao, X. et al. Evaluation and projection of temperature change in Northeast China. Journal of Meteorology and Environment, 37, 33-42 (2021).

27. Zhao, C. Y., Ren, G. Y., Zhang, Y. F. \& Wang, Y. Climate change of the Northeast China over the past 50 years. Journal of Arid Land Resources and Environment, 23, 25-30 (2009).

28. Guo, Z. M., Miao, Q. L. \& Li, X. Change characteristics of temperature in North China since recent 50 years. Arid Land Geography, 28, 176-182 (2005).

29. Kong, F. et al. Spatiotemporal patterns of different period climate warming rate in China (19612014). Journal of Beijing Normal University (Natural Science), 53, 426-435 (2017).

30. Su, J. Z., Wen, M., Ding, Y. H., Gao, Y. Q. \& Song, Y. F. Hiatus of global warming: a review. Chinese Journal of Atmospheric Sciences, 40, 1143-1153 (2016).

31. Ren, G. Y. et al. Recent progresses in studies of regional temperature changes in China. Climatic and Environmental Research, 10, 701-716 (2005).

32. 5] Tang, G. L. \& Ren, G. Y. Reanalysis of surface air temperature change of the last 100 years over China. Climatic and Environmental Research, 10, 791-798 (2005).

33. Han, L., Cao, Y., Chang, J. \& Cao, Y. Q. The study on change points in temperature and precipitation in Liaoning over the past 50 years. Journal of China Institute of Water Resources and Hydropower Research, 12, 310-315 (2014).

34. Zhou, X. Y. et al. Climate change characteristics and abrupt change analysis for Liaoning province, 1961-2009. Journal of Arid Land Resources and Environment, 27, 87-93 (2013).

35. Wang, F., Hong, L., Yasen, T., Xiong, J. D. \& Jiang, H. S. Spatiotemporal variations of air temperature in Songhua river basin. Research of Soil and Water Conservation, 27, 347-352 (2020).

36. Ren, G. Y. et al. Climate changes of China's mainland over the past half century. Acta Meteorologica Sinica, 63, 948-952 (2005).

37. Qiu, L. Y., Im, E. S. \& Kwon, H. H. Categorization of precipitation changes in China under $1.5^{\circ} \mathrm{C}$ and $3^{\circ} \mathrm{C}$ global warming using the bivariate joint distribution from a multi-model perspective. Environ. Res. Lett, 15, 124043 https://doi.org/10.1088/1748-9326/abc8bb (2020).

38. Zhang, J., Yu, J. S. \& Lai, W. L. Response of global warming to extreme precipitation increase over China. Journal of Beijing Normal University (Natural Science), 53, 722-726 (2017).

39. Ding, Y. H., Li, X. \& Li, Q. P. Advances of surface wind speed changes over China under global warming. Journal of Applied Meteorological Science, 31, 1-12 (2020).

40. Cao, Y. Q., Li, L. H., Lu, J., Zhang, R. N. \& Ning, Y. The effects of climate change on corn yield in Liaoning province.China Rural Water and Hydropower,132-137(2020)

41. Liu, Y. Y., Wei, X. L. \& Li, Y. F. Variation of sunshine duration and related driving forces in Jilin province during 1961-2012. Journal of Natural Resources, 30, 1367-1377 (2020). 
42. Pei, Y. H., Sun, S. \& Wang, C. L. Analysis on variation characteristics of the sunshine duration of recent 50 years in Heilongjiang province.Heilongjiang Agricultural Sciences,41-43(2012)

43. Yang, Y. H., Zhao, N., Hao, X. H. \& Li, C. Q. Decreasing trend of sunshine hours and related driving forces in North China. Theoretical and Applied Climatology, 97, 91-98 (2009).

44. Chen, S. Y., Zhang, K. L., Xing, X. B. \& Dong, A. X. Climatic change of sunshine duration in Northwest China during the last 47 Years. Journal of Natural Resources, 25, 1142-1152 (2010).

45. Zha, J. L., Shen, C., Zhao, D. M., Wu, J. \& Fan, W. X. Slowdown and reversal of terrestrial near-surface wind speed and its future changes over eastern China. Environ. Res. Lett, 16, 034028 https://doi.org/10.1088/1748-9326/ABE2CD (2021).

46. Wu, J., Zha, J. L., Zhao, D. M. \& Yang, Q. D. Changes in terrestrial near-surface wind speed and their possible causes: an overview. Clim. Dyn, 51, 2039-2078 (2018).

47. Zhang, R. H., Zhang, S. Y., Luo, J. L., Han, Y. Y. \& Zhang, J. X. Analysis of near-surface wind speed change in China during 1958-2015. Theor. Appl. Climatol, 137, 2785-2801 (2019).

48. McVicar, T. R., Roderick, M. L., Donohue, R. J. \& VanNiel, T. G. Less bluster ahead? Ecohydrological implications of global trends of terrestrial near-surface wind speeds. Ecohydrol, 5, 381-388 (2012).

49. Li, J., Liu, Z. H., Yu, Y., Wang, R. N. \& Ma, L. Analysis of variation characteristics and cause of evaporation in Liaoning province. Chinese Journal of Agricultural Resources and Regional Planning, 41, 27-35 (2020).

50. McVicar, T. R. et al. Global review and synthesis of trends in observed terrestrial near-surface wind speeds: implications for evaporation. Journal of Hydrology, 416/417, 182-205 (2012).

51. Jin, W. M., Ren, G. Y. \& Qu, Y. Change of surface pressure in Northeast China during 1961-2008. Plateau Meteorology, 30, 1661-1667 (2011).

52. 60] Lin, D. R. \& Xie, L. Y. Revelation of agro-meteorology learning from climate change 2014: impact, adaptation and vulnerability. Chinese Journal of Agrometeorology, 35, 359-364 (2014).

53. Tao, F. L. \& Zhang, Z. Climate change, high-temperature stress, rice productivity, and water use in Eastern China: a new superensemble-based probabilistic projection. Journal of Applied Meteorology and Climatology, 52, 531-551 (2013).

54. Wang, M., Li, Y. P., Ye, W., Bornman, J. F. \& Yan, X. D. Effects of climate change on maize production, and potential adaptation measures: a case study in Jilin province, China. Climate Res, 46, 223-242 (2011).

55. Xie, L. Y. et al. Updated understanding on the impacts of climate change on food production and food security. Progressus Inquisitionesde Mutatione Climatis, 10, 235-239 (2014).

56. Zhang, T. Y. \& Huang, Y. Estimating the impacts of warming trends on wheat and maize in China from 1980 to 2008 based on county level data. Int. J. Climatol, 33, 699-708 (2013).

57. Chen, X. Y. et al. Analysis on potential productivity and climatic influence factors of spring maize in Jilin.Crops,91-98(2016) 
58. Zhou, Y., Li, N., Dong, G. P. \& Wu, W. X. Impact assessment of recent climate change on rice yields in the Heilongjiang reclamation area of Northeast China. Journal of the Science of Food and Agriculture, 93, 2698-2706 (2013).

59. Hu, C. L. et al. Variation characteristics of rice climate suitability and its response to regional climate warming in Liaoning province. Acta Agriculturae Jiangxi, 33, 13-18 (2021).

60. Xiong, W. et a1. Impacts of observed growing-season warming trends since 1980 on crop yields in China. Reg. Environ. Change 14, 7-16 (2014)

61. Xiong, W., Conway, D., Lin, E. D. \& Holman, I. Potential impacts of climate change and climate variability on China's rice yield and production. Climate Res, 40, 23-35 (2009).

62. Zhang, W. J., Chen, C. Q., Jiang, Y., Zhang, J. \& Qian, H. Y. Comprehensive influence of climate warming on rice production and countermeasure for food security in China. Journal of AgroEnvironment Science, 39, 805-811 (2020).

63. Chen, Q., Geng, T., Hou, W. J. \& Chen, C. Q. Impacts of climate warming on growth and yield of spring maize in recent 20 years in Northeast China. Scientia Agricultura Sinica, 47, 1904-1916 (2014).

64. Tao, F. L., Zhang, Z., Zhang, S., Zhu, Z. \& Shi, W. J. Response of crop yields to climate trends since 1980 in China. Climate Res, 54, 233-247 (2012).

\section{Declarations}

\section{Acknowledgements}

We are grateful to Yan Gu and Shaofeng Bian for advice on the manuscript, and to all past and present members of the article team who have assisted in data collation. This work was supported by China Agriculture Research System of MOF and MARA (CARS-02-42).

\section{Author contributions}

Weiping Yan and Hongxiang Zhao: Formal analysis, Writing and original draft preparation; Lihua Zhang and Chen Xu: Methodology and Conceptualization; Guobo Tan, Ning Sun, Fei Li and Xiangmeng Meng: Investigation and Data curation; Weiping Yan and Yan Gu: Writing and review and editing; Shaofeng Bian : Funding acquisition. All authors contributed signifcantly to revisions of the manuscript.

\section{Competing interests}

The authors declare no competing interests.

\section{Figures}




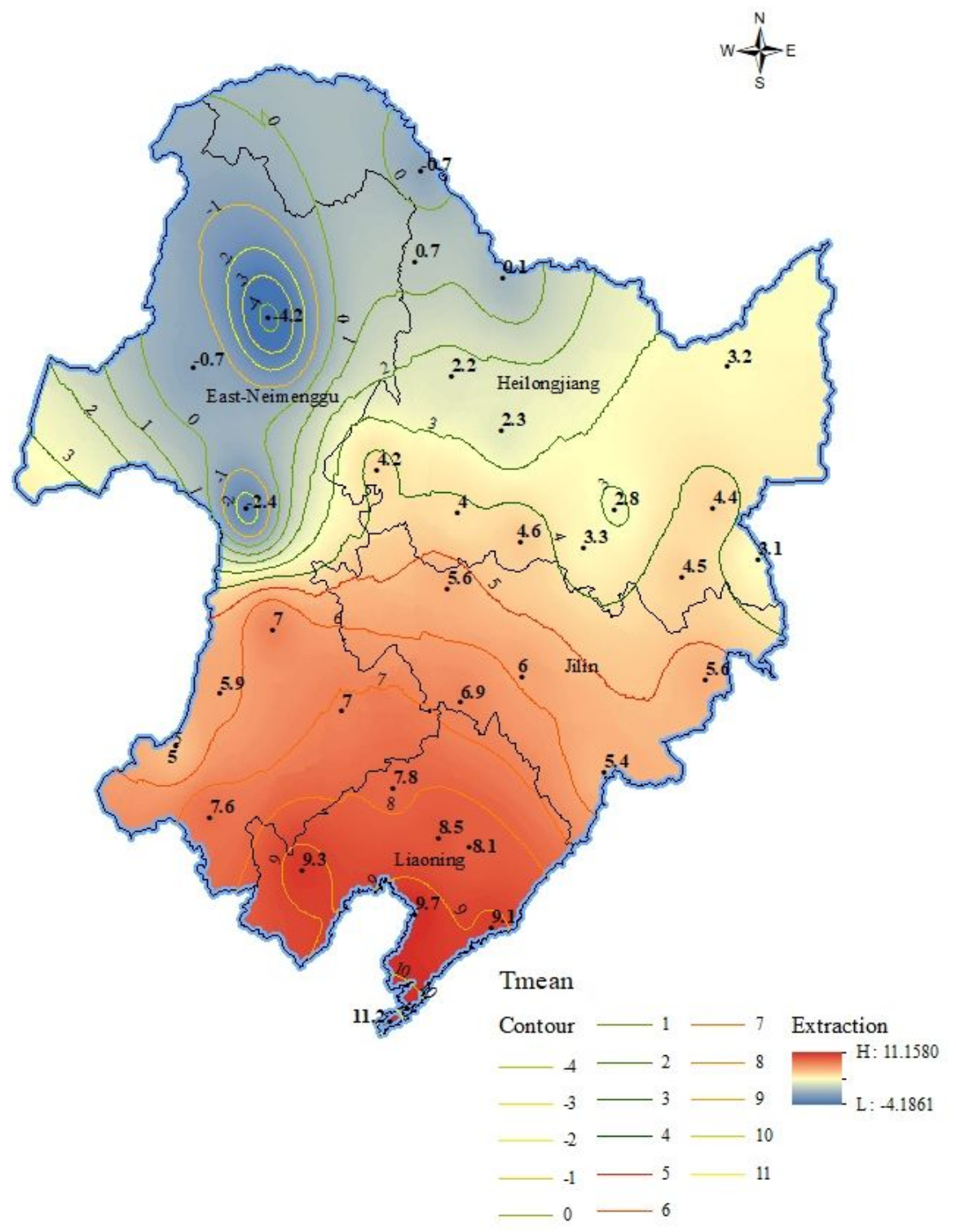

Figure 1

Spatial distribution of Tmean in Northeast China from 1971 to 2020. 

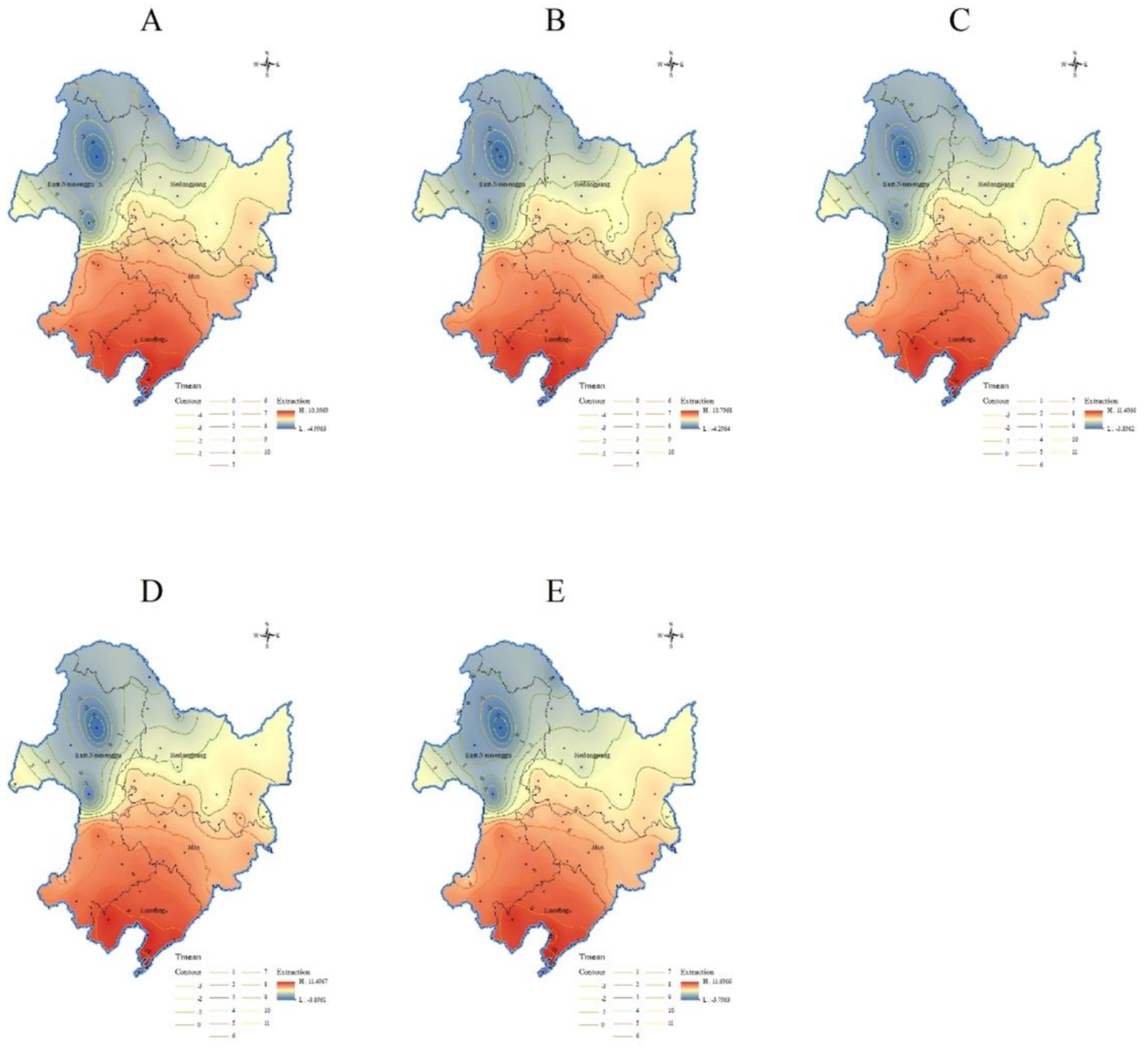

\section{Figure 2}

Annual Tmean distribution and variation in Northeast China in different periods from 1971 to 2020 . A: Distribution of annual Tmean in Northeast China from 1971 to 1980. B: Distribution of annual Tmean in Northeast China from 1981 to 1990. C: Distribution of annual Tmean in Northeast China from 1991 to 2000. D: Distribution of annual Tmean in Northeast China from 2001 to 2010. E: Distribution of annual Tmean in Northeast China from 2011 to 2020. 
A

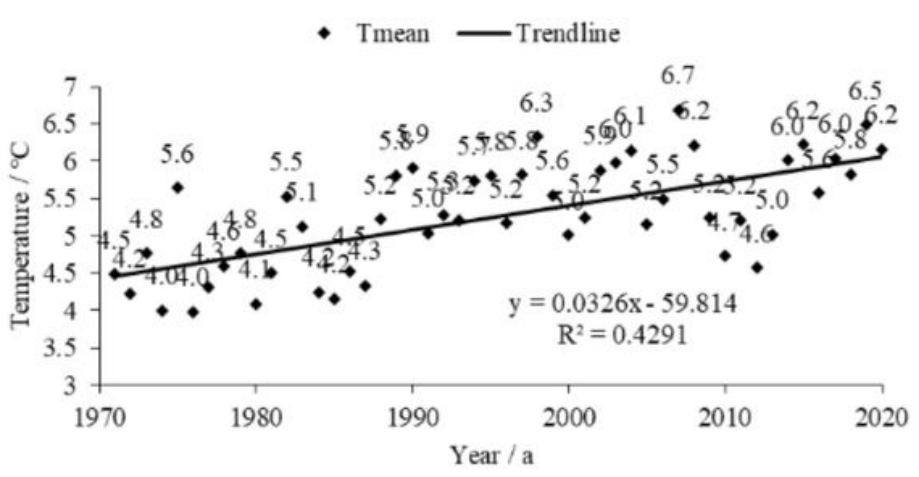

B

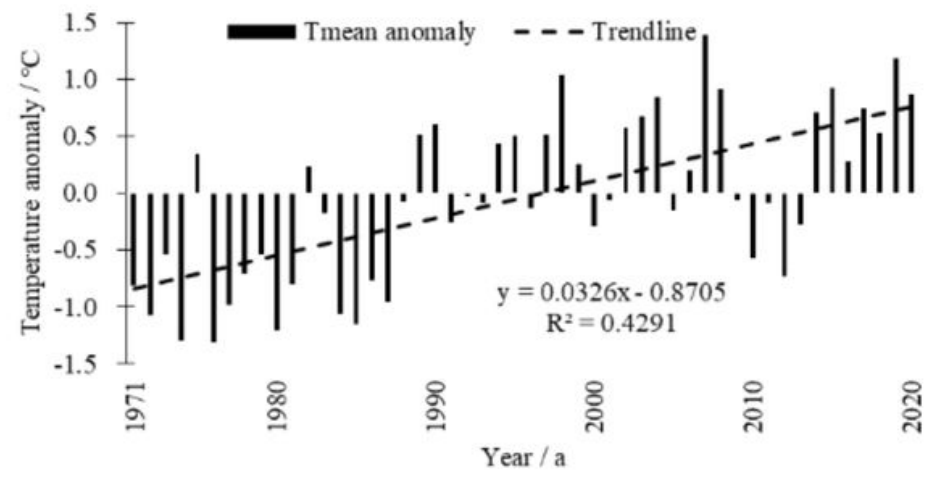

Figure 3

Interannual variation trend of Tmean in Northeast China from 1971 to 2020. A: Annual Tmean distribution from 1971 to 2020. B: Annual Tmean anomaly from 1971 to 2020.

Mann-Kendall mutation point test

$(\alpha=0.05)$

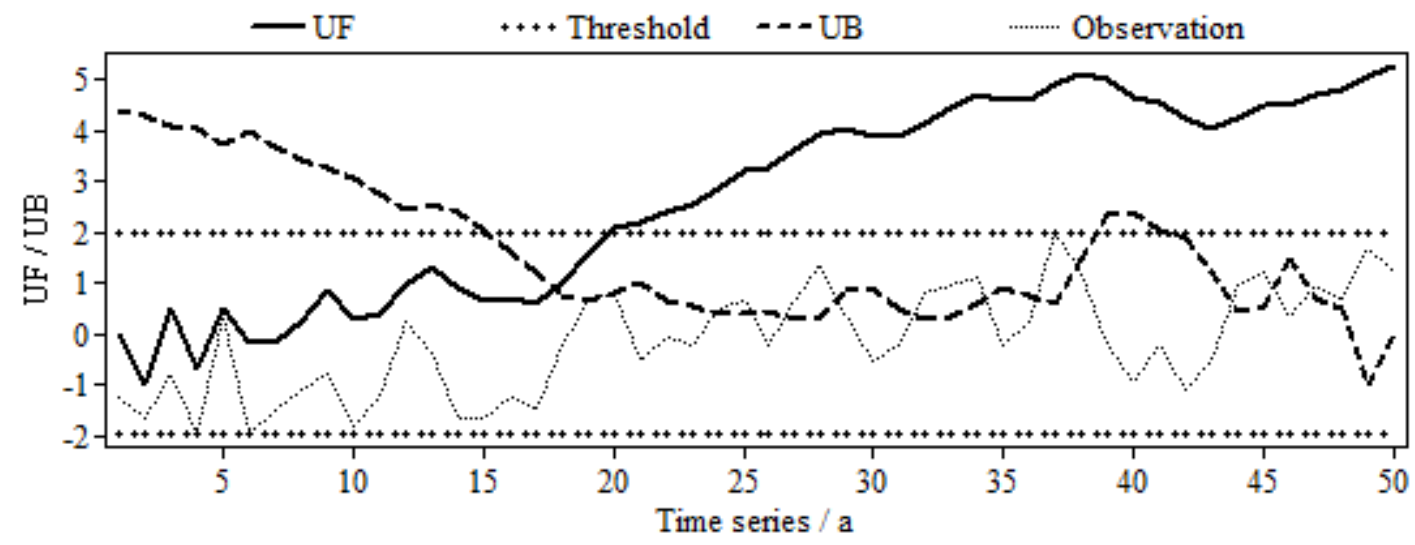

Figure 4

Mann-kendall mutation test of annual Tmean in Northeast China from 1971 to 2020. 


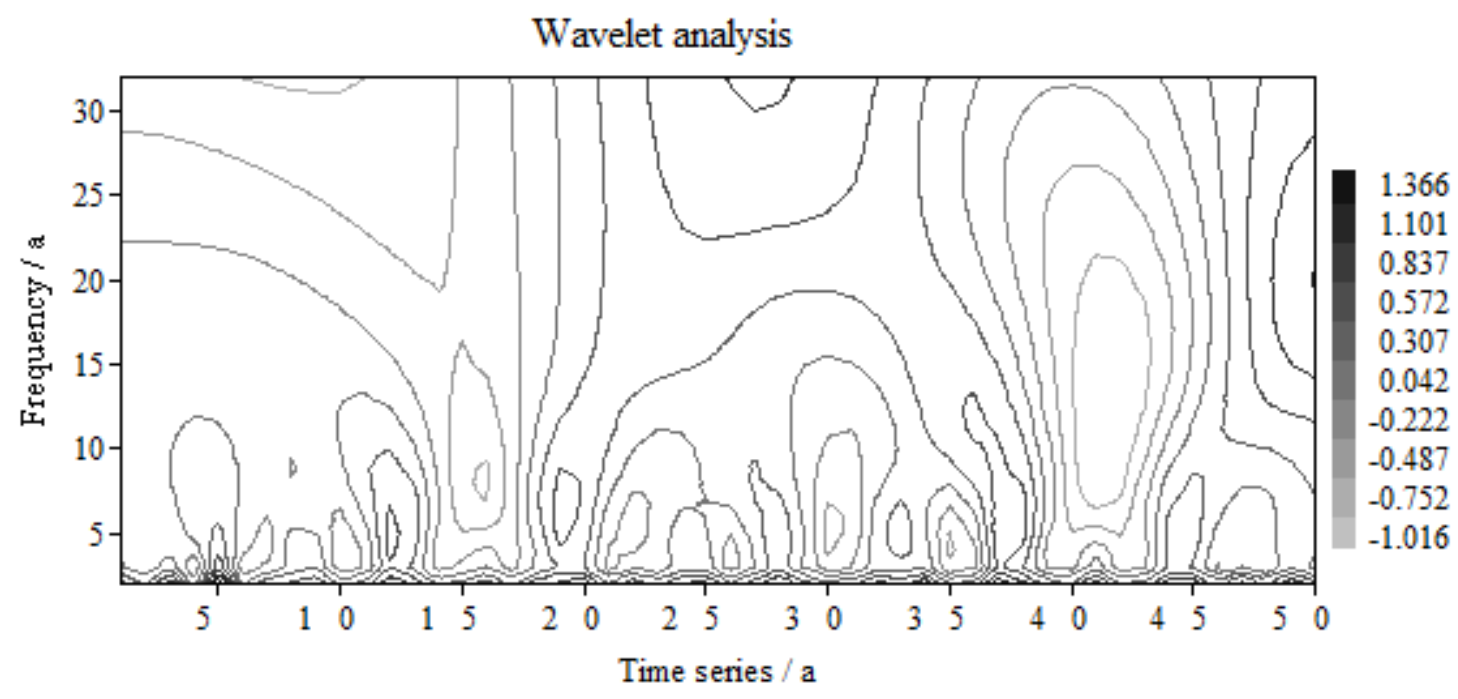

Figure 5

Wavelet analysis of annual Tmean in Northeast China from 1971 to 2020. 
A

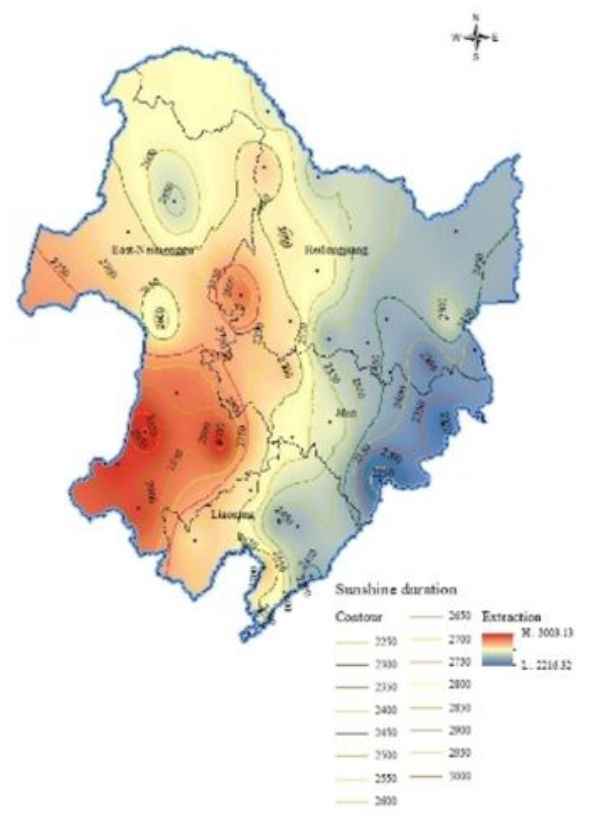

$\mathrm{C}$

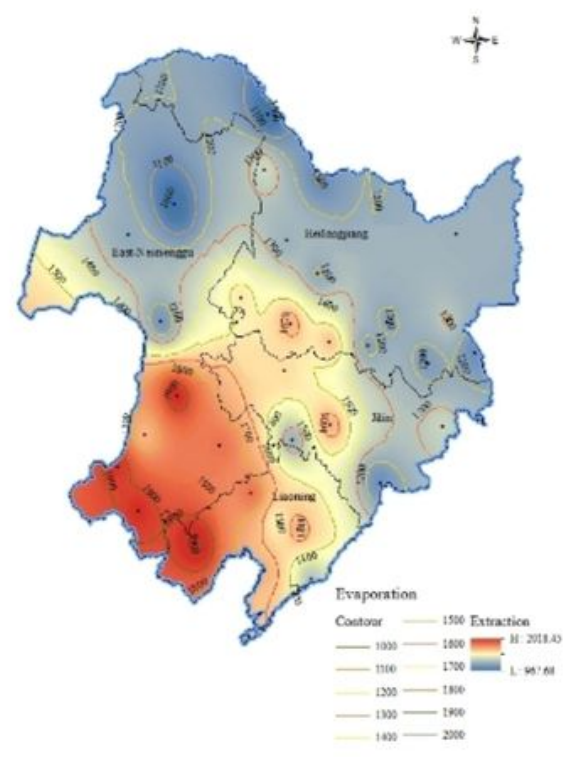

B

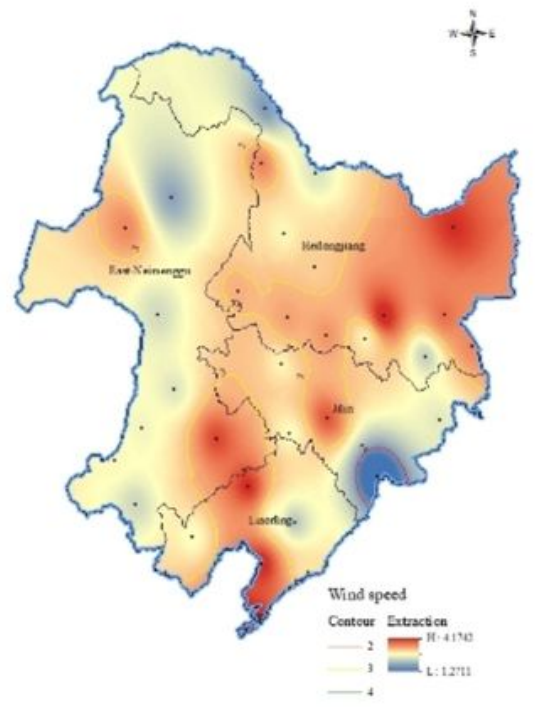

$\mathrm{D}$

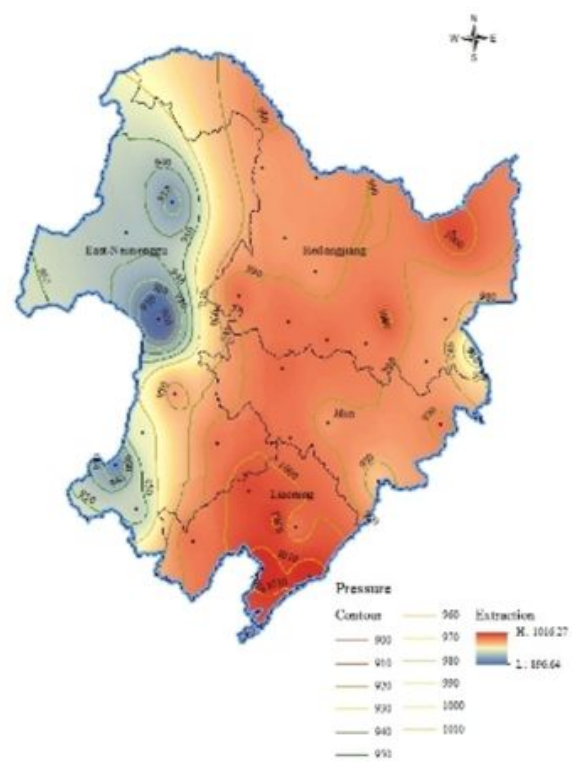

\section{Figure 6}

Spatial distribution of meteorological factors in Northeast China from 1971 to 2020 . Spatial distribution of average annual sunshine duration. B: Spatial distribution of average annual wind speed. C: Spatial distribution of average annual evaporation. D: Spatial distribution of average annual pressure. 


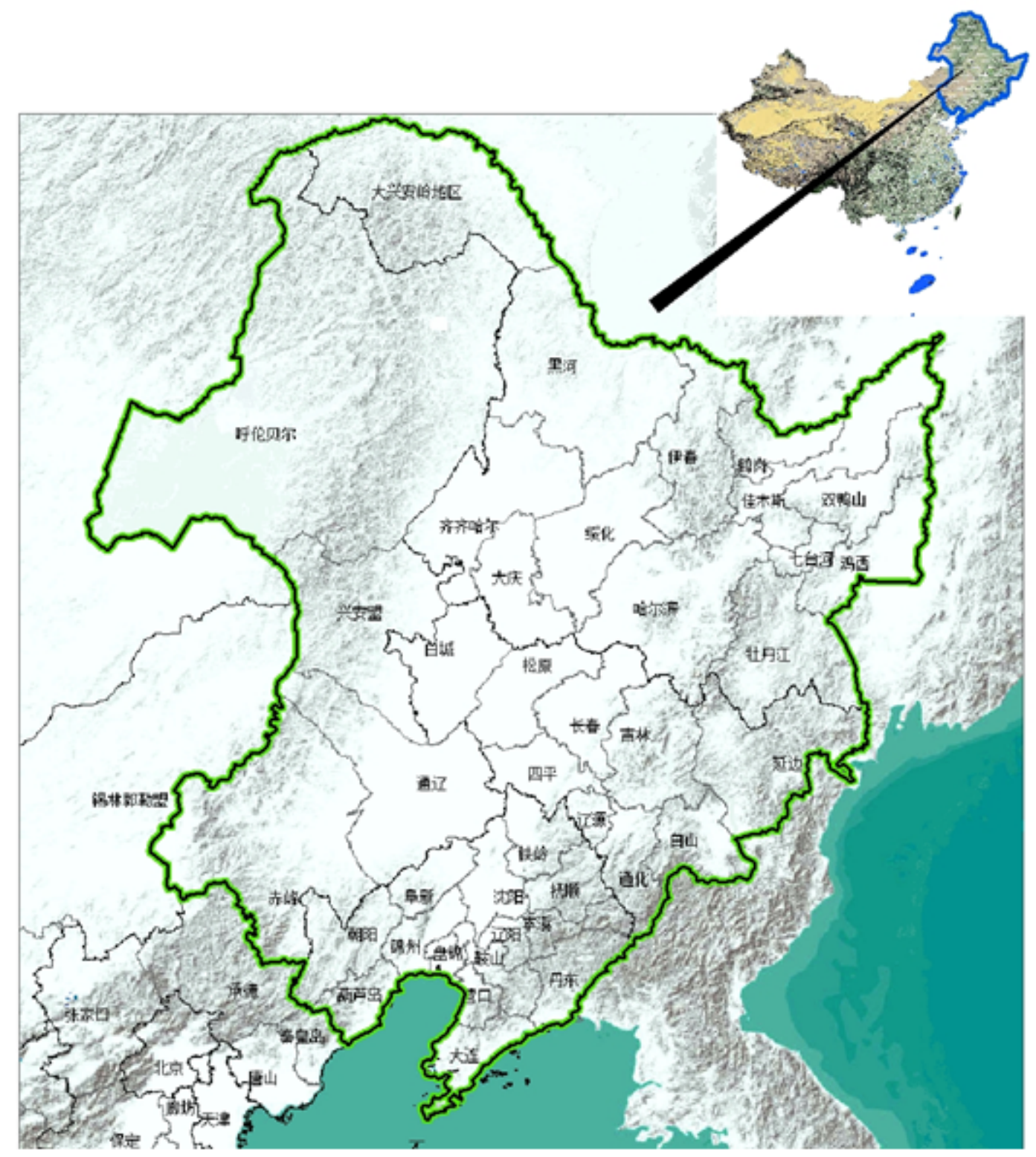

Figure 7

Division and location of Northeast China. 


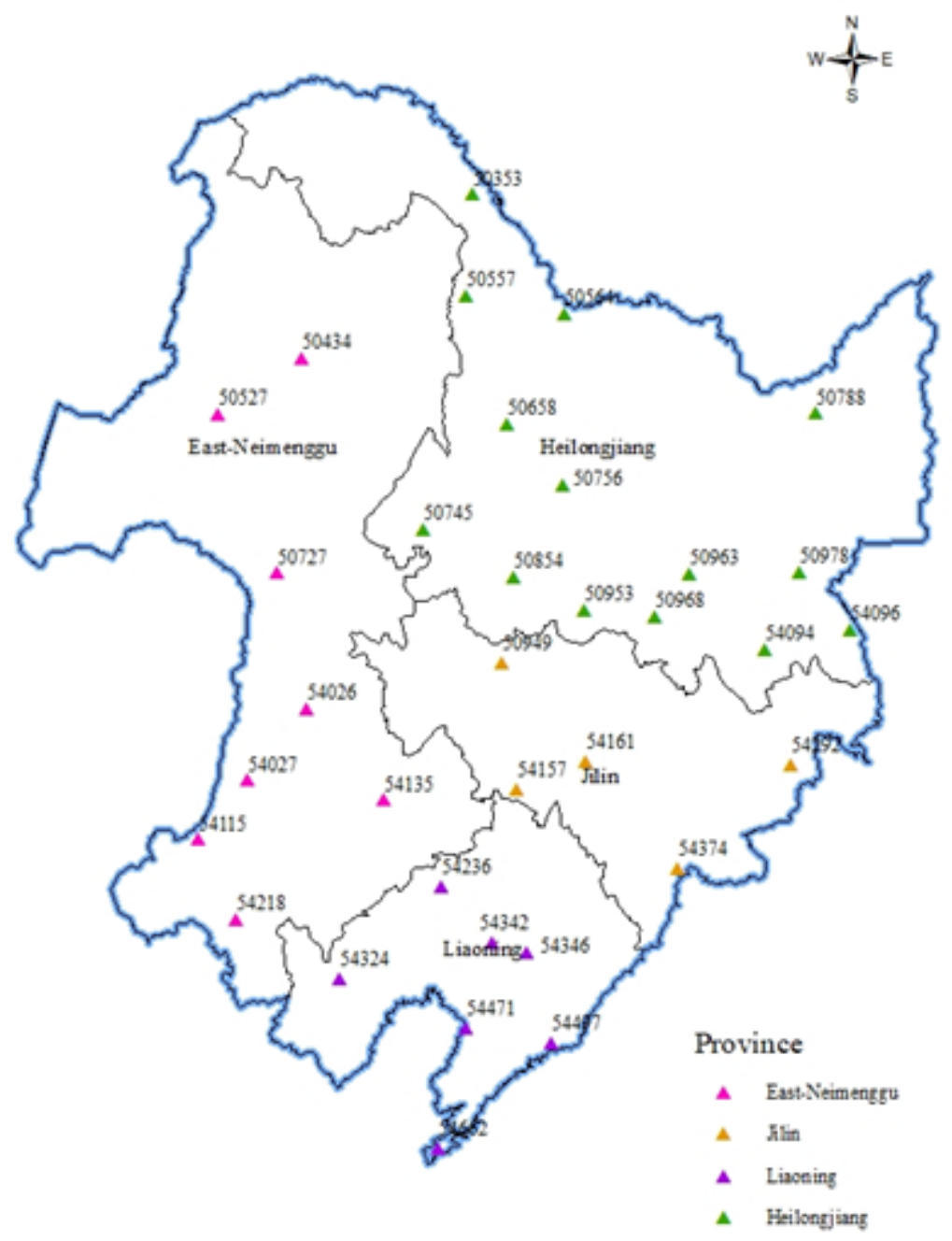

Figure 8

Location and station number of 34 ground international exchange stations in Northeast China. 